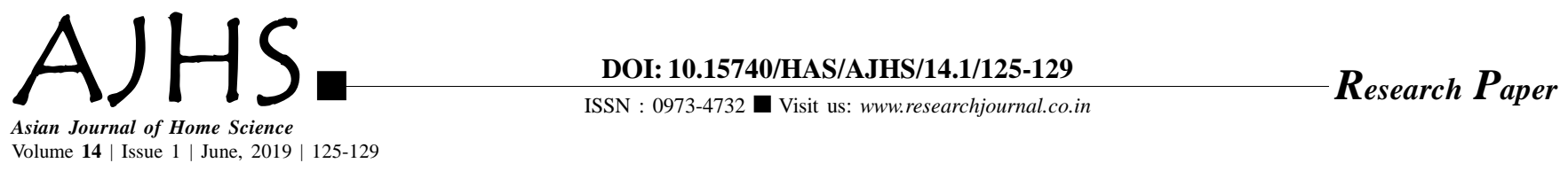

\title{
Comparison of seam puckering between light and medium weight woven cotton apparels: A study on lapped and edge neatening seam
}

\section{Poonam Oza and Namrita Kola}

Received: 01.03.2019; Revised: 26.04.2019; Accepted: 06.05.2019

See end of the paper for authors' affiliations Poonam Oza

P.G. Department of Home Science, Sardar Patel University, Vallabh Vidyanagar (Gujarat) India

Email: poonamoza8888@gmail. com
ABSTRACT : Evaluation of seam pucker is one of the most significant aspects for quality control in garment manufacturing. Seam puckers lead to aesthetically undesirable garments and may also cause inconvenience in wear. The purpose and objective of this study was to explore and scrutinize the impact of sewing parameters and seam angle on seam puckering for cotton fabric. An experimental design was prepared for the study which included two types of stitch and seam class and suitable sewing parameters like: sewing needle size, sewing machine type, sewing thread size, stitch density and seam angle on the seam pucker of light weight and medium weight woven cotton fabrics. In this study, fabric sample were sewn at $45^{\circ}, 60^{\circ}$ and $90^{\circ}$ angles with two different stitch and seam class. The $90^{\circ}$ signifies that the fabrics were sewn in weft direction, where as $45^{\circ}, 60^{\circ}$ means the fabrics were sewn in the warp direction. Seam puckering was estimated by objective method, by measuring the thickness of both the seamed and unseamed fabric. Seam puckering depends upon the warp and weft yarn covered in the seam and yarn linear densities, which can be represented as effective relative cover. It was observed that seam puckering was the lowest at seam angle $90^{\circ}$ (to the weft direction) in combination of lock stitch and overedge chain stitch in light weight fabric. Puckering percentage is higher at seam angle $60^{\circ}$ for chain stitch in lapped seam for light weight fabric. The findings of this study revealed that sewing parameters have a significant influence on woven fabric in relation to seam pucker. The study has also brought to light the behaviour of seams in the different stitch and sewing parameters on cotton fabric. The analyzed results will help manufacturers of apparels to select sewing parameters, to decide on stitch types for least pucker in the finished garment which would help to achieve quality seams to meet consumers' desire.

KEY WORDS: Seam puckering, Woven cotton fabric, Seam angle, Stitch, Seam, Effective relative cover

- HOW TO CITE THIS PAPER : Oza, Poonam and Kola, Namrita (2019). Comparison of seam puckering between light and medium weight woven cotton apparels: A study on lapped and edge neatening seam. Asian J. Home Sci., 14 (1) : 125-129, DOI: 10.15740/HAS/AJHS/14.1/125-129. Copyright@ 2019: Hind AgriHorticultural Society. 